Pressey, A.D. and Peters, L. D., "The coordinative practices of temporary organisations", Journal of Business and Industrial Marketing, forthcoming 2016.

\title{
THE CO-ORDINATIVE PRACTICES OF TEMPORARY ORGANISATIONS
}

\section{STRUCTURED ABSTRACT}

Purpose: The study explores the necessary mechanisms for coordination in complex industrial networks which are temporary in nature, known as temporary organisations.

Methodology: The study is based on two in-depth case studies conducted in the UK construction industry.

Findings: The study outlines the necessary mechanisms for coordination in temporary organizations - referred to as 'scaffolding practices - which ensure consistency (stability in terms of thinking and action), consensus (agreement) and co-constitutiveness (personal pledges and commitments).

Research implications: The study provides practical implications for situations where actors create temporary organizational specific logics. This 'logic' helps explain how actors are able to undertake tasks of finite duration where members lack familiarity and have competing loyalties.

Originality/value: The study is novel in that it represents the first extant attempt to examine 'temporary industrial organizations' where individuals from different (often competing) organizations collaborate on a task for a defined period of time and suggests how coordination may be achieved.

Article Classification: Research Paper

Key words: Temporary Organizations; Coordination; Construction Industry.

Word count: 9,004 (including references)

Acknowledgements: This work was supported by the British Academy (grant number SG101502).

[DOI 10.1108/JBIM-12-2014-0259] 
Pressey, A.D. and Peters, L. D., "The coordinative practices of temporary organisations", Journal of Business and Industrial Marketing, forthcoming 2016.

\section{INTRODUCTION}

This study examines the mechanisms that facilitate coordination in temporary industrial networked organizations (TOs), defined as major collaborations between organizations which focus on a specific outcome over a finite period of time. Such collaborations are not simply projects, and differ from the more commonly discussed project based collaboration in that they are collaborations between, rather than within, host organisations. As Bengtsson and Kock (2014: 185) recommend, we need to reflect on our theories and models that examine temporary projects particularly as "Traditional theories often presume that projects are organized within the boundaries of the firm, and therefore lack dimensions related to the continuous erosion of organization boundaries."

Despite the rise in popularity of temporary industrial networks, Bechky (2006) maintains that few organizational scholars have systematically examined the internal functioning of temporary organizational forms, and that organizational behaviour does not adequately account for the process by which coordination takes place in them in. Further, Pauget and Wald (2012) observe that although temporary forms of organizing are gaining in importance, little is known about how work in complex projects is actually accomplished and coordinated. In this study, we focus specifically on such coordination mechanisms to show that while traditional coordination and control mechanism (such as hierarchical reporting structures) may be absent, this does not mean that efficient and effective coordination of such temporary organisations does not take place. In fact, the role of coordination takes on a renewed importance in such organisational forms.

This study provides a novel first-hand account of coordination in a temporary industrial network and advances our understanding of complex modes of industrial organization. Further, this deepens our understanding of how coordination occurs in teams of diverse experts (cf. Bruns, 2013); an area of wider organizational study that has received limited attention (cf. Okhuysen and Bechky, 2009; Bechky, 2006). As we witness a growth in temporary organizations this contribution would appear timely in understanding temporary business-to-business networks.

Hence, we maintain that there is a paucity of research that examines (a) TOs as temporary inter-organisational networks and (b) the practices of such networks, particularly the coordinative practices, of temporary organizational and networked forms. This study seeks to redress this situation by reporting on a major study undertaken in the UK construction industry in which we identify practices that foster coordination in an interorganisational temporary organisation. These practices highlight how actors are able to

overcome challenges and foster coordination. The study concludes with implications and presents avenues for future research.

\section{TEMPORARY ORGANIZATIONS AS NETWORKS}

An extensive corpus of work on industrial projects of all hues exists, with in excess of 1000 articles having been published on the subject including related topics such as new 
Pressey, A.D. and Peters, L. D., "The coordinative practices of temporary organisations", Journal of Business and Industrial Marketing, forthcoming 2016.

product development and innovation studies, product management, sales force automation, customer-perceived value, purchasing and sales integration, to name but a few. Arguably a weakness in this line of project-based inquiry in industrial marketing has been to overlook the phenomena of temporary industrial networks and organizations, where in order to reduce risk, accelerate learning opportunities and pool organizational competencies, multiple companies temporarily collaborate on major initiatives. As such, "...classical definitions of projects are not wrong, just incomplete" (Turner and Muller, 2003: 1).

Janowicz-Panjaitan et al. (2009: 60) argue that studies of TOs are actually dispersed, and in fact often appear under labels such as temporary systems, temporary groups and, in particular, projects and project teams that do not include the word 'temporary'. Examples in the industrial marketing literature of related research where the term temporary is not used, include: Cardozo, Shipp and Roering (1992) who explore customer-linked strategy and partnerships; Wilkinson, Young, Welch and Welch (1998) who explore export groups as structuring devices for action learning in which knowledge and resource creating and selforganizing processes are nurtured, and whose processes in turn shape the evolution of interfirm relations and networks; Johnston and Hausman (2006) who use the metaphor of the extended family to explore how organizations involved in dyadic relationships must also consider the dynamics of being embedded in a network of inter-relationships; Tidström and Hagberg-Andersson (2012) who maintain that business relationships may evolve from cooperation to competition through chronological events involving information sharing, salesrelated and opportunistic activities between the individual companies and third parties, such as customers; Capaldo (2014) who concludes that simultaneous consideration of structural and relational embeddedness can enrich our understanding of network-based forms of organization and their impact on the outcomes of interorganizational cooperation; and Bygballe and Ingemansson (2014) whose findings show that construction companies are increasingly working more systematically to turn build-level ideas into company-wide knowledge, and are also increasingly concerned with establishing closer connections to customers and users, which have traditionally been weak. Consequently, while we have studies conceptually related to TOs in the business-to-business marketing, they are fragmented and dispersed within our literature.

Alternative forms of organising, in particular the dynamics of such forms, have been a topic of some interest, as evidenced by a special issue of the Scandinavian Management Journal published in 1995 which focused on temporary organisations and project management. However, the discussion of the terms 'temporary organisation' and 'projects' were interchangeable. In other words, temporary organisations were seen largely as (a) a phenomenon within organisations to manage projects and/or (b) temporary enactments of stable institutions (Lundin, 1995).

In contrast, we maintain that temporary organisations are not simply one particular form of project management, but are in fact characterised by individuals with not only different and diverse skill sets, but who are often based in different 'home' organisations. In this we differ from early definitions of temporary organisations in which TOs refer to "...a set of diversely skilled people working together on a complex task over a limited period of time" (Goodman and Goodman, 1976: 494). Instead, we align ourselves with more recent research on working relationships, such as 'intermistic relationships' which are short-term relationships defined as a "...close, collaborative, fast-developing, short-lived exchange

Pressey, A.D. and Peters, L. D., "The coordinative practices of temporary organisations”, 3 
Journal of Business and Industrial Marketing, forthcoming 2016.

relationship in which companies pool their skills and/or resources to address a transient, albeit important, business opportunity and/or threat" (Lambe et al., 2000: 212). Thus our shift in definition is to define temporary organisations not just in terms of temporal boundaries and diversity in skill sets, but also in the networked nature of temporary organisations as forms that span institutional boundaries as well. Temporary organisations happen not within organisations, but between organisations.

\section{COORDINATION, NETWORKS, AND LEARNING}

While organizational theorists have long understood that as organizations are faced with greater uncertainty, coordination becomes more challenging and complex (Galbraith, 1973; Thompson, 1967; Lawrence and Lorsch, 1967), our understanding of the coping mechanisms for dealing with the uncertainty and 'messiness' of temporary industrial networks is limited. However, the last two decades has witnessed a resurgence of scholarship on organizational coordination. In their recent review of the coordination literature, Okhuysen and Bechky (2009) observed that research in coordination has extended beyond organizational theory into a variety of disciplines such as computer science, information systems, and sociology of work. In a business-to-business context such interest is associated with research in network and relational competence as a prerequisite to manage networks and actors' capabilities (Pauget and Wald, 2012).

Theory in relational coordination argues that the effectiveness of coordination is determined on the one hand by the quality of communication among professionals in a work process, and on the other hand by the quality of their relationships (particularly the extent to which shared goals, shared knowledge and mutual respect are expressed) and is a type of professional relationship that is particularly relevant for coordinating work that is highly interdependent, uncertain and time-constrained (Gittell et al. 2006). The definition of coordination the present study draws on is provided by Faraj and Xiao (2006: 1156), where "...coordination is about the integration of organizational work under conditions of task interdependence and uncertainty." This is a particularly pertinent definition given that many TOs (such as construction) are undertaken in an atmosphere of uncertainty. In order to mitigate against this uncertainty, TOs must rely on the coordinative efforts of actors. Such efforts may be both formal and/or informal (Okhuysen and Bechky, 2009)

Another reason why interactions in networks are seen as an important area of research is that they help to promote learning, which is seen as playing a pivotal role in firm development within the network (Håkansson and Johanson, 2001). Knowledge and learning is important in construction settings (Robinson et al., 2005), both in terms of knowledge about the building and its function (houses, commercial buildings, roads, dams, etc.) and in terms of the construction process (Håkansson and Ingemansson, 2011). Although perhaps perceived as a sector with limited examples of best practice in terms of innovation or sophistication, the modern construction industry is one of virtual design tools and planning platforms and low energy technology solutions; hence the use of existing knowledge and the renewal of this knowledge is crucial for the modern construction company (Håkansson and Ingemansson, 2011). In contrast to prior industry dynamics (which were often characterised by adversarial relationships between firms), the last twenty years has seen a move to partnering between firms and " ... a shared culture without regard to organization 
Pressey, A.D. and Peters, L. D., "The coordinative practices of temporary organisations", Journal of Business and Industrial Marketing, forthcoming 2016.

boundaries" in the construction sector in an effort to improve performance (Construction Industry Institute, 1991:iv). Such industry-level changes emphasise the involvement of other parties, as product and process innovations often come from suppliers, architects and consultants and from the collaboration between them (Bygballe et al., 2010).

Not only does network membership increase learning opportunities, but such joint learning opportunities act as the glue that binds networks together (Holmen \& Pedersen, 2003). Thus, in contrast to theories of learning that focus on the information processing capabilities of learners, network learning focuses on the shared meaning constructed in situ in network contexts (Johnston, Peters \& Gassenheimer, 2006) and the communication and coordination practices that support this. As noted by Tywoniak (2007:53): "Knowledge is conceived as a structure validated through action, a process contextualized in individual experience and a system embedded in social and cultural experience." In such reciprocal learning relationships, individual learning is only a part of the process. Partners must also learn how to learn together, and learn how to exploit this new knowledge that makes them interdependent (Lubatkin et al., 2001).

TOs face a number of challenges that may inhibit coordination including the absence of familiarity with other actors' working practices, finite time to complete (often novel) tasks and actors with diverse skills and capabilities. As Lindner and Wald (2011) note, once a project is finished the constellation of people working together is resolved, fragmenting the project knowledge. In contrast to permanent organizations where departments and divisions act as knowledge silos, in temporary organizations routines and organizational memory hardly emerge. Thus, as Lindner and Wald (2011) point out, there is a lack of mechanisms for knowledge capturing, storing and disseminating and for organizational learning. Therefore, each TO is unique - it has no past to draw upon and limited future to anticipate.

Coordination, however, has largely been overlooked by scholars within the TO literatures. As Janowicz-Panjaitan, Bakker and Kenis (2009: 69) observe, few studies offer a primary focus on coordination within temporary organizations, instead relegating it to a subtheme of inquiry. As a consequence, the practices that members of TOs draw on to achieve their tasks would appear a central question to understanding the functioning of TOs. Against this background, the present study seeks to examine the mechanisms for coordination in TOs.

\section{METHODOLOGY}

\section{CASE STUDY SELECTION AND CONTEXT}

We base our study of coordinative practices in TOs through the exploration of two case studies of networks formed for the delivery of large scale construction builds. We use the term "build" rather than "project" as it is a common term used in the construction industry to refer to specific jobs, and allows us to focus on these types of jobs as examples of interorganisational TOs as opposed to intra-organisational project teams. Sampling of these construction builds was theoretical (Yin, 1994) based on the opportunities they provided to observe coordination in a TO. The prevailing conditions for both builds of temporariness, heterogeneity (multiple partners and work practices), uniqueness, and a lack of prescribed 
Pressey, A.D. and Peters, L. D., "The coordinative practices of temporary organisations", Journal of Business and Industrial Marketing, forthcoming 2016.

organizational routines to complete both builds at the offset, created a backdrop of inherent complexity (cf. Pauget and Wald, 2012).

These cases were chosen for three main reasons. First, because of the scope and significance of the builds; in both cases they were substantial new-builds (as opposed to the renovation, repair, or extension of existing buildings) and thus differed from the repetitive construction jobs studied by Kadefors (1995) in an earlier attempt to understand temporary organisations. Second, both included levels of innovation that challenged existing practices and technologies requiring new and innovative solutions to both construction processes and operational outcomes. Third, the nature of the contractual arrangement between the client and the build team was an important factor, as both were two-stage tenders. In a two-stage tender process, the technical proposals are separated from the fixed price which reduces the risk to the contractor. It also allows the contactor to engage with the design team at an earlier stage in the design process, and therefore provides learning opportunities that would normally not take place in a one-stage tender process.

The first case study, OfficeBuild, created office space and conference and training facilities. It commenced on-site construction after a planning stage lasting approximately nine months. The project design team involved nineteen members from nine different organizations. The decisions regarding this build evolved in two phases. In the first phase the building was designed for conference and training, with a mixture of small and large group meeting spaces. The planning of this phase of the build occupied the first six months of the timeline. While designing this part of the build, the design team left open the opportunity of an additional (second) floor to the building which could be added at a later stage of the design should the client approve it. As the final months leading up to the commencement of phase one of the build passed, the client muted the possibility of a second phase to the build. This would be an additional building offering more office space, built next to the phase one building, and connected to it at each level through corridors. Once again, the design team looked at the adjustments that would have to be made to accommodate this. Several months later it was still not clear if phase two would go ahead, and this caused concern for the project supervisors and the contractor. It was now becoming critical that a decision was made, and after much discussion the client team approved the building of the second phase of the project and the start of this second phase of production was to begin six months later.

The second case, PowerBuild, consisted of a combined heat and power (CHP) plant for a large-scale institutional user which would eventually allow the client to provide up to $90 \%$ of its own electricity needs. On-site construction began after a planning stage of approximately three years. The project design team involved nineteen members from eleven different organizations. Unlike OfficeBuild, this construction operated as two very distinct phases (the build and fit-out stages). In the first phase, the building (often referred to by the design team as the shell or the shed) was constructed. In the second phase, the power generation equipment was installed (referred to as the fit-out). Initial discussions concerning the CHP had been taking place for some time, and a number of different technologies had been considered. However, it was when the Fit-out team project administrator/manager met a CHP specialist who knew a design company that could develop the innovative technology they needed and provide them with the type of power generation they desired, that they then began to consider seriously the instigation of the project. In Table 1 we summarise the key features

Pressey, A.D. and Peters, L. D., "The coordinative practices of temporary organisations", 
Journal of Business and Industrial Marketing, forthcoming 2016.

of each case. The management teams were of approximately equal size on each build, and details are provided in Table 2.

While the role of the client and other members in the wider network (e. g. subcontractors and external stakeholders such as planning authorities) are no doubt important, we chose to focus our data collection and observations on the managerial and specialist designer TO members only (i.e. those on what is known in the construction industry as the design team). This provided a useful boundary in terms of coordination practices as these are the TO members who met on a regular and frequent basis, both formally and informally, and who dealt directly with the practical issues and problems that arose in relation to the project design and construction.

\section{Insert Tables 1 and 2 here}

\section{DATA COLLECTION, VALIDITY, AND RELIABILITY}

The data collected for this study consists primarily of 45 in-depth semi-structured interviews and two focus groups conducted with design team members of two UK construction builds over a period of twenty four months. In addition, 14 design team progress meetings were attended (eight for OfficeBuild and six for PowerBuild), in which official progress documents were collected and field notes were made. These meeting observations allowed for a deeper understanding of the data and provided evidence of validity through triangulation. The data were transcribed and coded using AtlasTI v6 software, following the coding procedure outlined by Strauss and Corbin (1998). The theme of the discussions focused on coordination practices and mechanisms within the temporary organization, following the work of Okhuysen and Bechky (2009) and Bechky (2006). A coding scheme was constructed based on these key aspects of coordination practices. Open coding was used to identify data relating to coordination within the two teams; the data were then examined for co-occurrence of coordination-related activities which results in three 'themes' or major categories of findings which were labelled by the researchers as (i.) consistency, (ii.) consensus and (iii.) co-constitution.

In order to aid internal validity, multiple perspectives were collected through interviewing actors at different points in the network (Yin, 1994), and through a process of pattern matching (Denzin and Lincoln, 1994; Eisenhardt, 1989) by comparing empirical patterns established in previous studies (e.g. Dubois and Gadde, 2002) and between each of the participants interviewed. In addition, during the course of the build we frequently drew on the expertise of a senior executive in the construction industry (who was not a member of either build team and was thus impartial) to help understand the issues arising from the data and our interpretations of them. This industry expert held a management board level position in a major UK construction company and had over thirty years' experience in the industry. To help ensure construct validity and to aid triangulation (Denzin and Lincoln, 1994), the different data collection strategies and sources (i.e. in-depth interviews, official progress documents and minutes of meetings and attendance at meetings) were employed in order to gain alternate perspectives of how knowledge is shared within the network. External validity through analytical generalisation (i.e. generalisation to theory using empirical evidence; Eisenhardt, 1989) was facilitated by conducting multiple case studies. Although this is limited in the present study (two case studies), cross-case comparison was possible. 
Pressey, A.D. and Peters, L. D., “The coordinative practices of temporary organisations”, Journal of Business and Industrial Marketing, forthcoming 2016.

Reliability refers to the extent that similar insights can be produced by subsequent researchers replicating the study (Denzin and Lincoln, 1994). Gibbert et al., (2008) suggest that transparency and replication are two primary methods to help aid reliability. Initially, transparency can be controlled through the use of a case study protocol, while replication can be controlled by creating a case study database. For the present study, a case study protocol was developed that outlines how the study was conducted and a database of case study notes, transcribed interviews, network pictures, minutes of meetings and observations of meetings, in order to facilitate case study replication (Leonard-Barton, 1990). Thus the observations of the researchers, together with the triangulation of data, help give the analysis and conclusions greater legitimacy.

\section{FINDINGS AND DISCUSSION: SCAFFOLDING PRACTICES IN TEMPORARY ORGANIZATIONS}

We draw on the metaphor of 'scaffolding' proposed by Okhuysen and Bechky (2009) which defines scaffolding practices as activities that are created by groups to impose order or structure on activities. Put simply, they are what needs to be done and by whom, and how the task will be completed. We derived three scaffolding practices inductively from the data. We have labelled them consistency, consensus, and co-constitutiveness, given their definitions from the Oxford English Dictionary as:

i. Consistency: “(a.) 'A settled condition' The condition in which matter coheres so as to 'stand together' or retain its form; viscous or firm condition; thickness, stiffness, firmness".

ii. Consensus: "(a.) Agreement in opinion; the collective unanimous opinion of a number of persons, accord, sympathy, common feeling".

iii. Co-constitutiveness: "(a.) The action of constituting; making, establishing”.

Collectively, we propose that these three conceptually overlapping practices provide coordination (or scaffolding) mechanisms in TOs. The remainder of the study examines these coordination mechanisms, illustrated with data from our two construction builds.

\section{CONSISTENCY}

Consistency refers to coordination mechanisms that ensure solidity, substance, and stability in terms of thinking and action in order to avoid task duplication or failure. The traditional view of TOs maintains that they lack the formal mechanisms and normative structure that 'permanent' organizations have (Meyerson et al., 1996). For example, Meyerson et al. (1996) argued that TOs lack stability and structure. However, in the organisational studies literature there are numerous examples of practices where organizational members create mechanisms for TOs to ensure a coherency in group practices.

One such practice in attempting to ensure solidity, substance, and stability in terms of thinking and action is the use of simple artefacts (known as boundary objects) which act as a mechanism to achieve coordination. Boundary objects (Star and Griesemer, 1989) create a shared meaning across diverse professional groups in networks. Such artefacts are valuable particularly when a task involves fixed time periods, numerous actors, and goals which may 
Pressey, A.D. and Peters, L. D., "The coordinative practices of temporary organisations", Journal of Business and Industrial Marketing, forthcoming 2016.

be relatively clear but the ways in which they can be achieved are not (Mason \& Easton, 2009). These tools are used to highlight conflicts, discrepancies, and other difficulties in performing the work (Okhuysen and Bechky, 2009). Studies have demonstrated that these simple artefacts (i.e. Excel spread sheets, architectural plans, and digital 3-D representations) act as a means to negotiate interpretations, practices and priorities, and as a way of capturing knowledge across diverse communities of practice (Cacciatori, 2008; Brown \& Duguid, 1991). They provide a fixed point of reference for actors, and thus contain 'memory' (Cacciatori, 2008), which may assist consistency and coordination between actors in TOs.

In the construction builds we studied a variety of 'living' documents (plans, reports, charts, maps) were employed. These were observed to be open to interpretation and were debated throughout the life of both builds. The engineers used technical drawings (translated into 3D models) that enabled them to envision the results of their actions. In meetings they often shared drawings and made impromptu sketches. Architects would draw sketches to illustrate their ideas, and the engineers would translate technical drawings into detailed solutions to specific problems. Technical drawings in particular were shared and discussed via email in order to ensure that the interpretation (or framing) of the information was understood correctly by those concerned and to provide an agreed blueprint for construction and an audit trail of design alterations. On the one hand, such boundary objects are situated in a particular frame of reference by the user, and can thus be open to different interpretations. Aligning such interpretations through the discussion of these boundary objects is one mechanism used to gain consistency. On the other hand, their interpretive fluidity could also highlight contradictions and barriers to consistency:

“...you're picking up a report that you've written and anyone can pick holes in any document because there's always of thinking round it. Now when you look at it and you think "Well, that's not necessarily right. I wouldn't have done..." You might read it, now you're reading it from the contractor's point of view and you're seeing people question it: "Well that's not necessarily right."

"...with the best will in the world, [name removed] cannot get his words and his drawings one hundred percent in the time and stage he's at, so there's always opportunities for a contractor to be able to manipulate that."

Boundary spanners may not be just objects, but also individuals themselves (Bechky, 2006; Barley, 1996). For example, in Barley's (1996) study of technicians, he observed that they acted as brokers between different professional groups to ensure that information is relayed between occupational groups. In the present study, one way that was utilized to ensure consistency was facilitated through the practice of novation - a largely overlooked phenomenon in the social sciences.

Novation is a legal term and refers to the act of replacing either an obligation or a party to an agreement with a new obligation or party. Novation is a common feature of network management in the construction industry (Doloi, 2008), where it is used to transfer members of the original design team on earlier phases of a construction build (e. g. architects and engineers) from the client-centred design team to the contractor's build team for the later stages of actual construction. The act of novation in these construction builds helped maintain 
Pressey, A.D. and Peters, L. D., "The coordinative practices of temporary organisations", Journal of Business and Industrial Marketing, forthcoming 2016.

a consistency in knowledge throughout the life of both builds, but could also bring challenges in terms of new working practices and relationships:

"They [the novated individual] then become part of our team almost. It's almost as if we are one big team because you are all working towards a common goal."

"...sometimes you don't even notice the change [being novated to the contractor's team], sometimes it can be absolutely horrendous, you know, it can be horrendous but, touch wood, I would say 95\% of the time it's a fairly smooth transition but you do get that odd glitch..."

Thus, consistency may come at a cost. Tensions may arise between the novated individual, their loyalty (as a former member) to the original client team, and their new alliance to the contractor's firm. One aspect of TOs that has been curiously overlooked is the fact that its members belong to 'home' institutions that may typically be ardent competitors for much of the time (i.e. on other construction builds) with the contractor firm to which the individual has been novated. This is a form of what has been termed 'coopetition' where both elements of cooperation and competition are visible between competitors at a fixed point in time (Bengtsson and Kock, 2000). The construction industry is a singular example in this regard, as companies are frequently co-operating on builds whilst simultaneously competing to win business on other contracts. One respondent offered the following sporting analogy:

"This one reminds me a bit more, of like, the Ryder Cup, in golf. Where you have a game that's played by individuals, and suddenly they have to be a team, for the Ryder Cup. But after the Ryder Cup, they go back to playing against each other. And therefore, you've got this issue of "Who's on my team at this point in time? And how is that going to enhance the project? And then what happens when I'm not on their team, anymore?"

This implies that while actions aimed at gaining consistency through the use of boundary objects and boundary spanning individuals may foster knowledge and understanding in the TO, it may also cause tensions and conflicts to surface. Gaining consistency is therefore a complex and dynamic process whose outcomes may be both productive and/or counterproductive, depending on the history, context, and aspirations of the TO members. We thus propose that this complex dynamic is a defining feature of efforts to gain consistency in TOs:

P1: Using both boundary objects and boundary spanning individuals as coordination mechanisms in TOs to facilitate consistency of knowledge and understanding may on the one hand offer solidity and stability in performing tasks, but on the other hand may also introduce tensions due to the coopetive nature of TO relationships.

\section{CONSENSUS}

While consistency ensures stability in terms of thinking and action in order to avoid task duplication or failure, consensus refers to achieving a common or working agreement 
Pressey, A.D. and Peters, L. D., "The coordinative practices of temporary organisations", Journal of Business and Industrial Marketing, forthcoming 2016.

among members and creating a common perspective (Okhuysen and Bechky, 2009). Examples of these practices abound in the organization studies literatures, for example Faraj and Xiao (2006) report how health professionals share patient protocols in order to create a common mental model of patient condition and treatment options.

One of the complexities of TOs (and observed to some degree in both construction builds studied), is that there was there rarely one 'correct' way to undertake what could often be novel tasks. One example is the work of an acoustic engineer who had to ensure that combined heat and power plant in PowerBuild did not exceed certain noise levels when active. There were a number of different, and alternative, technologies that could be used to accomplish this. It was thus his task to not only present what (in his view) was the best solution, but to bring the rest of the team (including the client) on-board with him. Such conditions may be exacerbated when trade professionals and engineers with very different backgrounds and training are called onto each build as their expertise was needed. Thus, consensus may be a hard-won battle with alternatives and compromise as regular features of its emergence.

“And I think with engineering there's no clear path to it. There're so many different paths to do. It's being able to take those and narrow it down, review it, narrow it down, review it. And then you come out with one that meets..."

"...people join half way through and so I do what I do and try and listen and compromise if I have to..."

Trust is particularly important in TOs (Grabher, 2002), as it is premised on trusting an individual to perform a task. The problem most TOs will face, however, is establishing trust between actors that may be unfamiliar with one another. This situation is further exacerbated by the finite (and often limited) time TOs have to complete their task. Why then, would most TOs not fail in the wake of mistrust and uncertainty between actors when deciding who should undertake what particular tasks? To help explain this, Meyerson et al. (1996) introduced the notion of swift trust in temporary groups, which involves the willingness to suspend doubt and bring trust to a given situation rather than create it (Janowicz-Panjaitan et al., 2009). Both construction builds studied were routinely faced with novel tasks that could not be easily anticipated or addressed through common practices. These required actors to demonstrate flexibility and to develop swift trust of their fellow professionals' competencies:

"And you can form a contractual link but you don't necessarily get the trust and that way you're all sitting with your arms folded, learning back across the table. But if you're leaning forward as we are talking, getting closer and closer necessarily because of trust and understanding and that sort of thing that makes for a better project because you get this "Hang on a minute your problem is that. But actually what if I suggest this?" Rather than "Well it's your problem mate get on with it."

This professional competency-based trust was frequently seen to be earned in part through actors' learning how to put their point across; several actors talked openly of "...defending your expertise" on both builds. The structural engineer on OfficeBuild stated that: "...you can only go so far as a team, but on site, and at a greater level of detail, decisions may be made 
Pressey, A.D. and Peters, L. D., "The coordinative practices of temporary organisations", Journal of Business and Industrial Marketing, forthcoming 2016.

by individuals." This was echoed by the mechanical and electrical engineer who observed that one of the most common problems in the temporary organizations he had been a part of was:

“...one which seems to come up is - I wouldn't say it's defending but it's almost defending your expertise because a lot of people - yes, everyone's got an expertise but they'll always try and sway it from their point of view and it's more a global one and it always comes in as an item."

In the two construction builds studied the absence of familiarity and potential distrust was largely overcome by a trust in the role and the professional training (and anticipated professionalism) and background of the individuals involved. This is consistent with studies on group performance where actors may lack familiarity with other team members (Liang et al., 1995).

"[We have built] a 'Circle of Trust,' ... that we will get through it, which we have done. And it's not cost any of us any money or caused any of us any problems, which is a lovely way to work. The test probably is if you have a proper problem. [Laughter]. But hopefully we're professional enough not to have a proper problem."

Therefore, trust is founded on the expectation that actors have certain role competence (McEvily et al., 2003; McAllister, 1995), which can be reinforced by actors' sharing their knowledge and demonstrating their competence (Reagans et al., 2005). This implies that personal integrity, both given and received, was a cogent feature in relations between team members. Therefore, both of these coordination mechanisms play a role in establishing consensus in TOs. Neither defending their own expertise in the face of other TO members, nor demonstrating flexibility and trust in their fellow professionals' competencies, was likely to succeed alone. It is the dynamics that result from the continual ebb and flow associated with both aspects of such trust that allows the emergence of consensus in the TO. We therefore propose the following:

P2: Developing a common culture and shared meaning in situ in the TO and achieving a common perspective on design solutions was achieved in part through the coordination mechanisms of actors defending their expertise to others in the TO on the one hand, and exhibiting competency-based trust to other professionals in the TO on the other hand.

\section{CO-CONSTITUTIVENESS}

The typical TO is thought to be less hierarchical (Miles, 1964; Palisi, 1970) and more reliant on interpersonal coordination (Bechky, 2006), than is the case in other organizational forms. To help understand the phenomenon of team working within TOs given these conditions we employ the concept of co-constitutiveness provided by Easton et al. (2012), which refers to commitments between actors to undertake certain tasks. We utilize this concept to illustrate how individuals 'buy-in' to TO goals and objectives, (which effectively serve as the governance mechanisms for the planned termination of TOs) by completion of key tasks. Overcoming disagreements and attempts to define tasks and actors' responsibilities were frequently observed in both construction builds studied: 
Pressey, A.D. and Peters, L. D., "The coordinative practices of temporary organisations", Journal of Business and Industrial Marketing, forthcoming 2016.

\begin{abstract}
"We have a great deal of upfront thinking at a very early stage of other options, other people, what other things are doing and, you know, really trying to get their side of what can be delivered to the customer."

"We have what we call Project Manager Review Meetings where we all get around the table once every four months. And that's a sort of a knowledge sharing, brain storming, type exercise."
\end{abstract}

Time pressures to reach agreements and decision making may compromise both commitment and commitments between TO team members (Janowicz-Panjaitan et al., 2009). It is, in fact, these time pressures in construction builds that help foster commitment; the failure to complete a construction build on time normally carries significant financial penalties and also may be taken into account by future clients when deciding which companies to award contracts. This led to the simple construction mantra often repeated on both builds that: "You've got to build it all and construct it in the time." Hence, a sense of common purpose pervaded both construction builds; this was the possibility of collective success but also the possibility of collective failure in terms of a significant build over-run. Bringing in TO partners early in the design phase of the build was one way of fostering overall commitment to the build, and making specific commitments deliverable:

The beauty of this job really is that we have been involved early so, as soon as someone starts talking about "Oh I think we can do it like this." You can say "Yes, you know that could be done that way, but in our experience, we've tried that before and this happened, so could we not consider doing this?" And you know maybe it's more expensive, but ultimately it could be a better job. You know a far better job for just a few pounds more. Or you could say "Yes, that's a brilliant design, it's a brilliant solution, but we could offer you this or we could consider this, as a not quite as good, but you'll save yourself half the money." type of thing. And when they need to save quite a lot of money they embrace those sort of conversations a lot.

The high levels of uncertainty in both builds encouraged significant levels of actor inclusiveness, where attempts were made to ensure that no actor was left out of key decision making: "We play together for the good of the team." This was further endorsed by actors creating future pledges or commitments by offering favours to group members. This helped support trust between actors but also established a 'store' of favours to potentially call on if required:

"...the relationship of all working together, the acknowledgement of us, that [the architect] in places, was going above and beyond. So if he's a bit behind on a provisional sum or something, I can't hammer him too hard because I know he's helped me out over there. But we try and just keep people focussed. And I think we've got - well we have - we've got through it all in a timely manner."

Physical distance and proximity between actors affects the extent to which organizational members are able to communicate and interact (Allen, 1977). As Okhuysen and Bechky 
Pressey, A.D. and Peters, L. D., "The coordinative practices of temporary organisations", Journal of Business and Industrial Marketing, forthcoming 2016.

(2009) note, such physical proximity can create 'lateral visibility' that helps coordinate work and foster liking between group members. One final mechanism for facilitating commitments and buy-in between actors was co-location practices, which helped overcome the lack of familiarity between group members. This took the form of not just the usual practices of team meeting, but also social activities and team building exercises:

"He then took the step of organising a team building exercise which incurred at that particular time didn't incur a great deal of money other than people's, individual's time. But he is of the mind to do as I said earlier, take the team out of the working environment into a social environment and spend a bit of money in some form of entertainment whether it be a meal or something like that. Or whatever it is, doesn't really matter what it is but to help break down those barriers so that people get to know and understand each other. And then it becomes this better understanding and a trust thing."

This implies that tasks themselves form a key component of TO coordination. How tasks are defined, who is made responsible (and how) for their execution and completion, and the pressures of time and task uncertainty all impact the co-constitutiveness of TO members. We therefore propose the following:

P3: Member buy-in and co-constitutiveness (through forming commitment and commitments) in TOs is established via the coordination mechanisms of defining tasks and responsibilities, using time pressures and uncertainty as a way to establish a sense of common purpose, and the co-location of TO members.

A summary of the mechanisms that may lead to coordination through consistency, consensus, and co-constructiveness in TOs are outlined in Table 3.

\section{Insert Table 3 here.}

\section{CONCLUSIONS AND IMPLICATIONS}

In this study we have outlined what we refer to as 'scaffolding practices' - practices that facilitate coordination in complex temporary industrial networks with blurred organizational boundaries, and put forward three such practices; consistency, consensus and co-constitution, that help facilitate temporary network effectiveness. The study provides an account of coordination in a temporary industrial network and advances our understanding of complex temporary modes of industrial organization.

Specifically, these three practices in intense network learning environments contribute to the performance of temporary industrial networks via: (i.) fostering consistency through the use of boundary objects and boundary spanning individuals which fosters knowledge and understanding in the TO; (ii.) establishing consensus through actors defending their expertise and competency-based trust; and (iii.) ensuring co-constitutiveness through forming commitment(s) between actors. These three practices represent how actors in TOs are able to 
Pressey, A.D. and Peters, L. D., "The coordinative practices of temporary organisations", Journal of Business and Industrial Marketing, forthcoming 2016.

contribute to their effectiveness or performance through their timely execution and completion, and provide network learning opportunities.

The scaffolding practices outlined emphasise how actors create TO specific logics. This logic helps explain how actors are able to undertake tasks of finite duration where members lack familiarity and have competing loyalties. Both theory and practice cite examples of a number of temporary industrial marketing initiatives between competitors such as product collaborations, shared technology and R\&D investment, new market entry, and joint distribution and marketing investments (such as cobranding). These are more than mere 'projects', and our understanding of them and discourse should reflect this.

Our contribution represents perhaps the first extant attempt in the marketing literature to study the phenomena of TOs; our study recognizes that the conception of the project is no longer an internal organizational 'tool' but frequently a temporary mode of organizing between organizations. As such, we encourage further study on these growing phenomena.

\section{IMPLICATIONS FOR RESEARCH, PRACTICE AND SOCIETY}

A number of areas for future research merit specific exploration; the challenges faced in TOs; what constitutes temporariness and degrees of 'temporary'; and the discourse used to describe TO marketing initiatives would seem sensible places to start. It may be that our understanding of networks, and some of our widely accepted and established ways of explaining networks (e.g. in terms of actors, resources and activities), may require revisions to specifically incorporate the temporary and transient.

In addition, our discipline may need to revisit some of our core concepts and lexicon. A key area of study for the last two decades in marketing and the business-to-business literature has been on long-term relationships; as such, there is a need to rethink some of our concepts given that relationships between actors such as those in TOs are not long-term in nature nor are they purely transactional in the conventional sense, but they still need to establish states of trust and commitment, cooperation and lines of communication. If we want our theory development in industrial marketing to be both relevant and useful to our audience then we cannot afford to ignore phenomena such as TOs.

The present research highlights certain practices that provide the 'scaffolding' for temporary industrial networks which come with implications for managerial practice, including:

The necessity for short courses, workshops, and social events that bring experts together and help provide some explanation of role expectations across diverse expert domains. These should assist managers by helping them to facilitate interactions that enrich relations both within the focal temporary organisation itself, and more broadly between the TO and the respective home organizations of actors. In addition, these sorts of events should assist managers in working on their 'soft' management skills, which may be more important than 'hard' systems of organizing in TOs where nonhierarchical leadership structures exist. Further, as many actors working in TOs do so in isolation towards a common set of objectives, structured events can help locate expertise (i.e. not just the know-how but the 'know-who'). 
Pressey, A.D. and Peters, L. D., "The coordinative practices of temporary organisations", Journal of Business and Industrial Marketing, forthcoming 2016.

The role and importance of co-location on builds and exposure to professionals' work in other fields. Managerial implications here included the capacity for actors to trouble-shoot problems, and the ability for actors to disseminate not just explicit knowledge (such as designs and plans) but also and experiential knowledge that is developed in the course of a TO and may be useful in the future of the TO or else in future TO endeavours.

The practice of using shared objects. This would seem important in facilitating the completion of pressurized tasks where effective coordination is necessary and where actors in industrial networks come together for short (and often intense) periods of time without necessarily any prior contact or anticipated future collaboration. This would provide a fixed point of reference for actors, and given that objects contain 'memory' this would assist consistency and coordination between actors in TOs.

Finally, we can assert a number of implications for society. Given the likely proliferation of temporary organizational forms in the future, business-to-business scholars should arguably engage with these types of transient networks in order to engage in emergent trends in broader society, particularly due to the growth of the service-based economy and knowledge-based economy. Hence, society will likely witness more instances of cross-domain working between actors with diverse expertise and professional backgrounds will be required to achieve collective goals in numerous industries. In order to retain its relevance, business-to-business scholarship should contribute to this debate and help explain how experts in temporary industrial networks are able to more effectively work alone ... together.

\section{REFERENCES}

Allen, T. (1977), Managing the flow of technology, MIT Press: Cambridge, MA.

Barley, S. R. (1996), "Technicians in the workplace: Ethnographic evidence for bringing work into organization studies", Administrative Science Quarterly, Vol. 41, pp. 404441.

Bechky, B. A., (2006), "Gaffers, gofers, and grips: Role-based coordination in temporary organizations", Organization Science, Vol. 17, pp. 3-21.

Bengtsson, M., and Kock, S. (2000), "Coopetition in Business Networks - To Cooperate and Compete Simultaneously", Industrial Marketing Management, Vol. 29 No.5, pp. 411:426.

Bengtsson, M., and Kock, S. (2014), "Coopetition - Quo vadis? Past accomplishments and future challenges", Industrial Marketing Management, Vol. 43 No. 2, pp. 180-188.

Brown, J. S., \& Duguid, P. (1991), " Organizational Learning and communities-ofpractice”, Organization Science, Vol. 12, pp. 198-213.

Bruns, H. C. (2013), "Working alone together: Coordination in collaboration across domains of expertise", Academy of Management Journal, Vol. 56 No. 1, pp. 62-83.

Bygballe, L. and Ingemansson, M. (2014), "The logic of innovation in construction", Industrial Marketing Management, Vol. 43 No. 3, pp. 512-524.

Bygballe, L. E., Jahre, M., and Sward, A. (2010), "Partnering relationships in construction: a literature review", Journal of Purchasing and Supply Management, Vol. 16, pp. 239253. 
Pressey, A.D. and Peters, L. D., "The coordinative practices of temporary organisations", Journal of Business and Industrial Marketing, forthcoming 2016.

Cacciatori, E. (2008), "Memory objects in project environments: Storing, retrieving and adapting learning in project-based firms", Research Policy, Vol. 37 No. 9, pp. 1591160.

Capaldo, A. (2014), "Network governance: A cross-level study of social mechanisms, knowledge benefits, and strategic outcomes in joint-design alliances", Industrial Marketing Management. Vol. 43 No. 4, pp. 685-703.

Cardozo, R. N., Shipp, S. H. and Roering, K. J. (1992), "Proactive Strategic Partnerships: a New Business Markets Strategy", Journal of Business \& Industrial Marketing, Vol. 7 No. 1 , pp. $51-63$.

Denzin, N. K., and Lincoln, Y. S. (1994), Handbook of qualitative research. Sage, Thousand Oaks, CA.

Doloi, H., (2008), "Analysing the novated design and construct contract from the client's, design team's and contractor's perspectives", Construction Management and Economics, Vol. 26 No. 11, pp. 1181-1196.

Dubois, A. and Gadde, L. (2002), "The construction industry as a loosely coupled system: implications for productivity and innovation", Construction Management and Economics, Vol. 20, pp. 621-631.

Easton, G, Lenney, P., and Gilchrist, A., (2012), "The co-constitutiveness nature of organizations and industrial networks: A critical realist approach", 28th Industrial Marketing and Purchasing (IMP) Conference, Università Cattolica del Sacro Cuore, Rome.

Eisenhardt, K. M. (1989), "Building theories from case study research", Academy of Management Review, Vol. 14 No. 4, pp. 532-550.

Faraj, S., and Xiao, Y. (2006), "Coordination in fast-response organizations", Management Science, Vol. 46, pp. 1155-1189.

Galbraith, J. R. (1973), Designing Complex Organizations. Addison-Wesley, Reading, MA.

Gibbert, M., Ruigrok, W., and Wicki, B. (2008), "What passes as a rigorous case

study?", Strategic Management Journal, Vol. 29, pp. 1465-1474.

Gittell J.H. (2006), "Relational coordination: coordinating work through relationships of shared goals, shared knowledge and mutual respect", In Relational Perspectives in Organizational Studies: A Research Companion (Kyriakidou O. \& Özbilgin M.F., eds), Edward Elgar Publishers, Cheltenham.

Grabher, G. (2002). "Cool Projects, Boring Institutions: Temporary Collaboration in Social Context", Regional Studies, Vol. 36 No. 3, pp.205-214.

Goodman, R. A., and Goodman, L. P. (1976), "Some Management Issues in Temporary Systems: A Study of the Professional Development and Manpower-The Theatre Case", Administrative Science Quarterly, Vol. 21, pp.494-500.

Håkansson, H., and Ingemansson, M. (2011), "Construction companies and how they acquire knowledge through business interaction", The IMP Journal, Vol. 5 No. 2, pp.67-78.

Håkansson, H., and Johanson, J. (2001) "Business Network Learning - basic considerations", in Håkansson, H. and Johanson, J. (eds) Business Network Learning, Pergamon: Amsterdam.

Holmen, E. and Pedersen, A. (2003), "Strategizing through analysing and influencing the network horizon", Industrial Marketing Management, Vol. 32 No. 5, pp.409-418.

Janowicz-Panjaitan, M., Bakker, R., and Kenis, P. (2009), "Research on temporary organizations: the state of the art and distinct approaches toward "temporariness", In P. Kenis, M. Janowicz-Panjaitan and B. Cambré (eds) Temporary organizations: prevalence, logic and effectiveness, Edward Elgar: Northampton, MA. 
Pressey, A.D. and Peters, L. D., "The coordinative practices of temporary organisations", Journal of Business and Industrial Marketing, forthcoming 2016.

Johnston, J. and Hausman, A. (2006), "Expanding the marriage metaphor in understanding long - term business relationships", Journal of Business \& Industrial Marketing. Vol. 21 No. 7, pp. $446-452$.

Johnston, W. J., Peters, L. D. and Gassenheimer, J. B. (2006), "Questions about Network Dynamics: Characteristics, Structures, and Interactions", Journal of Business Research, Vol. 59, pp. 945-954.

Kadefors, A. (1995), "Institutions in building projects: Implications for flexibility and change”, Scandinavian Journal of Management, Vol. 11 No. 4, pp. 395-408.

Lambe, C. J., Spekman, R. E., and Hunt, S. D. (2000), "Interimistic relational exchange: Conceptualization and propositional development",. Journal of the Academy of Marketing Science, Vol. 28 No. 2, pp. 212-225.

Lawrence, P. R. and Lorsch, J. W. (1967), Organization and Environment: Managing Differentiation and Integration. Graduate School of Business Administration, Harvard University, Boston, MA.

Leonard-Barton D. (1990), "A dual methodology for case studies: synergistic use of a longitudinal single site with replicated multiple sites", Organization Science, Vol. 1 No. 3, pp. 248-266.

Liang, D. W., Moreland, R.L., \& Argote, L. (1995), "Group versus individual training and group performance: The mediating role of transactive memory", Personality and Social Psychology Bulletin, Vol. 21, pp. 384-393.

Lindner, F. and Wald, A. (2011), "Success factors of knowledge management in temporary organizations", International Journal of Project Management, Vol. 29 No. 7, pp. 877888.

Lubatkin M, Florin J and Lane P (2001), "Learning together and apart: A model of reciprocal interfirm learning", Human Relations Vol. 54, pp. 1353-1382.

Lundin, R. (1995), “Temporary organisations and project management”, Scandinavian Journal of Management, Vol. 11 No. 4, pp. 315-318.

Mason, K. and Easton, G. (2009), "Boundary Objects and Buyer - Seller Relationships", 25th IMP-conference, Marseille, France.

McAllister, D. J. (1995), Affect- and cognition-based trust as foundations for interpersonal cooperation in organizations, Academy of Management Journal, Vol. 38, pp. 24-59.

McEvily, B., Perrone, V., and Zaheer, A. (2003), Trust as an organizing principle, Organization Science, Vol. 14, pp. 91-103.

Meyerson, D., Weick, K. E., and Kramer, R. M. (1996), "Swift trust and temporary groups", in R.M. Kramer and T.R. Tyler (Eds.), Trust in organizations: Frontiers of theory and research, Sage Publications: Thousand Oaks, CA.

Miles, M. B. (1964), "On temporary systems", in M.B. Miles (ed.), Innovation in education, Teachers' College, Columbia University: New York, NY.

Okhuysen, G. A., and Bechky, B. A. (2009), "Coordination in organizations: An integrative perspective", The Academy of Management Annals, Vol. 3 No. 1, pp. 463-502.

Palisi, B. J. (1970), "Some Suggestions about the Transitory-Permanence Dimensions of Organizations", British Journal of Sociology, Vol. 21, pp. 200-206.

Pauget, B. and Wald, A. (2013), "Relational competence in complex temporary organizations: The case of a French hospital construction project network", International Journal of Project Management, Vol. 31 No. 2, pp. 200-211.

Reagans, R., Argote, L., and Brooks, D. (2005), "Individual experience and experience working together: Predicting learning rates from knowing who knows what and knowing how to work together", Management Science, Vol. 51, pp. 869-881. 
Pressey, A.D. and Peters, L. D., "The coordinative practices of temporary organisations", Journal of Business and Industrial Marketing, forthcoming 2016.

Robinson, H, Carrillo, P., Anumba, C. and Al-Ghassani, A. (2005), "Knowledge management practices in large construction organizations", Engineering, Construction and Architectural Management, Vol. 12 No. 5, pp. 431-445.

Star, S. L. and Griesemer, J. R. (1989), "Institutional ecology, "translations" and boundary objects: Amateurs and professionals in Berkeley's Museum of Vertebrate Zoology, 1907-1939”, Social Studies of Science, Vol. 19, pp. 387-420.

Strauss, A. and Corbin, J. (1998), Basics of Qualitative Research (2nd Ed.). Sage: London, UK

Thompson, J. D. (1967), Organizations in Action. McGraw-Hill, New York.

Tidström, A. and Hagberg-Andersson, A. (2012), "Critical events in time and space when cooperation turns into competition in business relationships", Industrial Marketing Management, Vol. 41 No. 2, pp. 333-343.

Turner, J. R. and Muller, R. (2003), "On the nature of the project as a temporary organization", International Journal of Project Management, Vol. 21, pp. 1-8.

Tywoniak S (2007), "Knowledge in Four Deformation Dimensions", Organization, Vol. 14 No. 1, 53-76.

Wilkinson, I., Young, L. C., Welch, D. and Welch, L. (1998), "Dancing to success: export groups as dance parties and the implications for network development", Journal of Business \& Industrial Marketing, Vol. 13 No. 6, pp. 492 - 510

Yin, R. K. (1994), Case study research: design and methods. Sage: London. 